\title{
Anaesthesia influence on glycaemia and body temperatures (first results)
}

\begin{abstract}
Background: The negative effect of the patient's temperature decrease is well known among surgeons and anaesthesiologists. The influence of critical situations including operation stress on glycaemia levels and evolution was also reported. The link between the two factors has remained rather unclear. Disposing a device/ $\mathrm{ADD} /$ allowing the continuous measure of core/deep and superficial body temperatures and their difference (dT) evolution we have tried to differentiate the role of anaesthesia and surgery in glycaemia and temperature evolution in rats and humans.
\end{abstract}

Method: 40rats were used and investigated during and immediately after anaesthesia alone and after thoracic surgery under the same anaesthesia. A group of 5 healthy not anesthetized volunteers and 5 informed consenting patients undergoing digestive surgery was also investigated. ADD was used for temperature measures, $\mathrm{pH}$ meter or strips - for glycaemia measure.

Results: Use of ADD device composed of 2 digital temperature captors, an analysing processor and registrar has allowed a continuous recording of the temperature regimen of the body and has shown that anaesthesia by itself can lead to significant hypothermia and to death if correction is not provided. Glycaemia levels varied in different ways: without correction they could dangerously either increase or decrease. Their decrease under normal level was a bad prognostic sign. Correlation between glycaemia and dT was not evident. Surgery has only deepened the effect of anaesthesia. In clinics the described effects were less expressed because of permanent empiric correction.
Volume 6 Issue I - 2018

\author{
Coulic Very,' Martin M, ${ }^{2}$ Dobos SA, ${ }^{2}$ \\ Devriend TJ, ${ }^{2}$ Novikov VN ${ }^{3}$ \\ 'ULB Translational Medicine Laboratory, Belgium 2CHU \\ Brugmann, departments of Biomedical Equipment, a, Digestive \\ Surgery, b, Intensive Care Unit, c, Belgium \\ ${ }^{2} \mathrm{CHU}$ Brugmann, departments of Biomedical Equipment, a, \\ Digestive Surgery, b, Intensive Care Unit, c, Belgium \\ ${ }^{3}$ VN Sklifosovski Scientific Research Emergency Institute, Russia
}

Correspondence: Coulic Very, ULB Translational Medicine Laboratory, Avenue JJ Crocq 2, 1020 Brussels, Belgium,

Tel 32-477-25-74, Email coulic.very@belgacom.be

Received: December 12, 2017 | Published: February 01, 2018

Conclusion: Anaesthesia and surgical intervention were confirmed to influence significantly glucose metabolism and energetics of the body. ADD device can be used as a testimony of temperature production and release that is of energetic balance of the organism. The dT continuous registration, besides glycaemia levels recording may be the basis for an adequate and quick monitoring of the patient's condition.

Keywords: anaesthesia, glucose metabolism, body temperatures, energetic balance, digestive surgery

and superficial (Ts) temperatures of the body and their difference $(\mathrm{Tc}-\mathrm{Ts}=\mathrm{dT}) .^{14,15}$ This device has proved to be useful in the diabetes treatment when coupled with an insulin pump, programmed by the results of dT evolution. ${ }^{16-2}$

So it could be interesting to use this ADD for clearing the respective role of anaesthesia and surgery in temperature per operative disorders and establish a parallel with the results of glycaemia investigation. In this work we try to consider apart and differentiate the influence of anaesthesia (which can decrease the basal metabolism) from the influence of the surgical act itself, hoping to find means of the patient's management optimization.

\section{Materials}

The experimental part of the study was conducted on 40 white laboratory rats: males, BW 350-400g, displayed in 2 equal series: anaesthesia only and anaesthesia plus surgery (Table 1). After induction with Fluorotane ${ }^{\circledR}$ ( $4 \%$ during 1 minute/100gBW) all rats were given intra peritoneal injection of Nembutal (pentobarbital $0.075 \mathrm{mg} / 100 \mathrm{~g} \mathrm{BW})$, Temgesic ${ }^{\circledR}(0.2 \mathrm{ml})$ and subcutaneous Atropin Sulfate $(1 \%-0.2 \mathrm{ml})$. Ambient temperature was $22-24^{\circ} \mathrm{C}$. surgery has appeared thanks to a new device called ADD (apparatus for diabetes diagnosis) which continuously registers core/deep (Tc) 
Table I Experimental series

\begin{tabular}{|c|c|c|c|c|}
\hline Subjects & Series & Number & Observation delay & Remarks \\
\hline \multirow[t]{6}{*}{ Rats } & Anaesthesia only & 20 & & Euthanasia at days I-7 \\
\hline & with warming/cooling & 8 & & \\
\hline & without intervention & 12 & & \\
\hline & Anaesthesia + Surgery & 20 & & \\
\hline & thoracic & 10 & Up to 13 months & Euthanasia at days $7-400$ \\
\hline & abdominal & 10 & 2days & $<4-48$ hour survival \\
\hline Total & & 40 & & \\
\hline
\end{tabular}

In 7 cases of the first group, after 1-2hour observation warming of the animals by a lamp (air temperature up to $30^{\circ} \mathrm{C}$ ) was started and maintained during 1hour or more depending on the animal's reaction i.e. till the Tc reached $38^{\circ} \mathrm{C}$. In 8 ases, $10 \%$ or $5 \%$ glucose solution bolus was administrated respectively per mouth $(0.2 \mathrm{mlx} 2)$ or subcutaneously $(0.4 \mathrm{ml})$. In 5 cases no intervention was undertaken. In the second group table warming $\left(39^{\circ} \mathrm{C}\right)$ was maintained during the thoracic operations.

The clinical part involved 5 informed volunteers were tested without anaesthesia and 5 consenting informed patients were investigated during severe high abdominal surgery, performed under usual classic anaesthesia using Propofol or Etomidate or Ketalar as inductors and Sufentanyl for the main analgesia. During intervention they received perfusion with Hartmann solution.

\section{Methods of investigation}

Temperatures were evaluated by usual room thermometer and body temperatures by the ADD device. In its last modification the device was composed of a double temperature digital sensor, a processor and an interface for communication with insulin and glucose pumps (Figure 1). The last were not used in the present study which was only observational. The sensors were included at a $4.5 \mathrm{~cm}$ distance from each other (to avoid temperature influence on each other) into an isolated catheter of $4 \mathrm{~mm}$ diameter enclosed into a thin, hermetic, waterproof and one-using polyethylene membrane. When the catheter was placed in the rectum the inner sensor being at the top of the catheter was situated at the level of the deep haemorrhoidal venous plexus in human, at the hepatic angle of the rat colon. It registered the core or deep temperature $(\mathrm{Tc})$ supposed to reflect thermogenesis.

\section{ADD-CGIT}

\section{Schematic diagram}

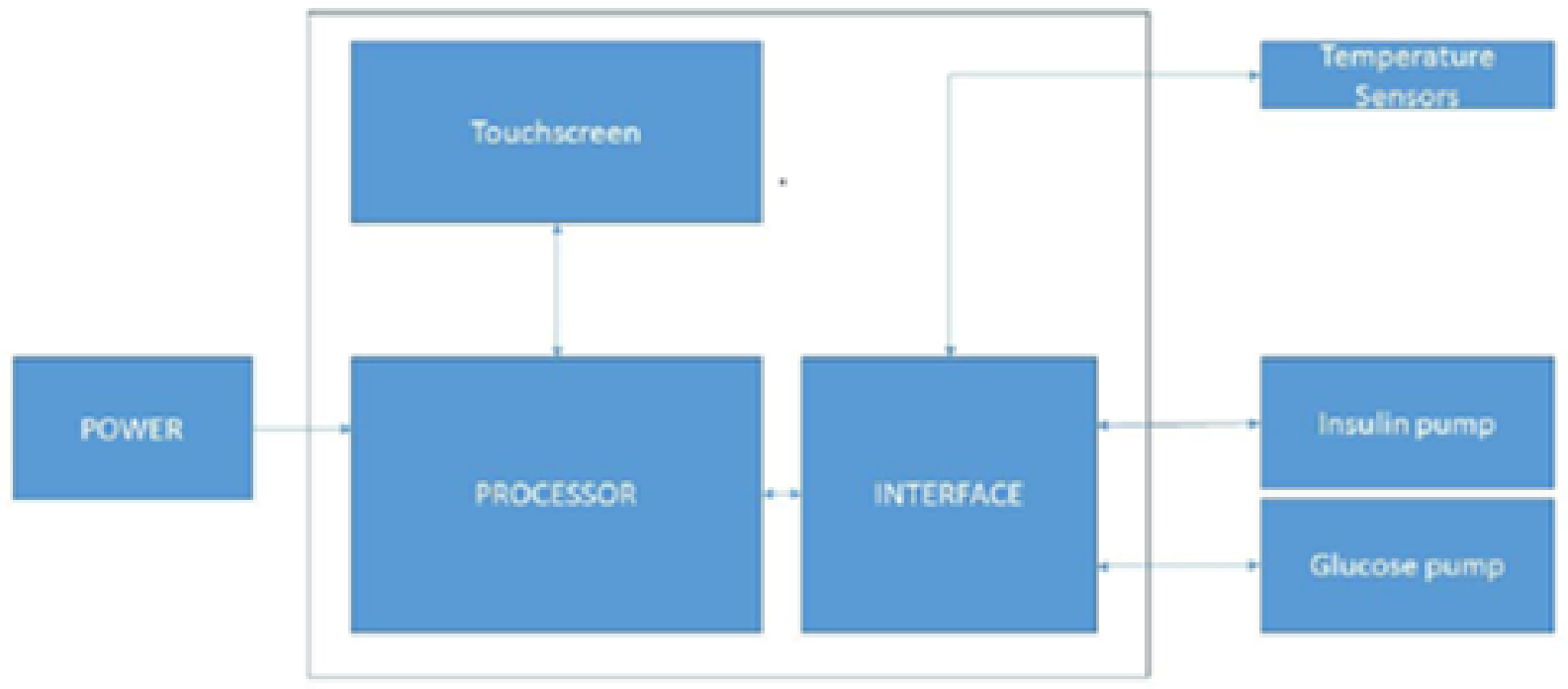

Figure I Schema of the used device (Apparatus for Diabetes Diagnosis and CGT Complex for Insulin and Glucose Therapy). The device was used only in observation regiment (ADD). 
In humans as well as in animals, the lower sensor was placed just above the external anal sphincter and registered the superficial temperature (Ts) of the subcutaneous para-rectal fat.

Preliminary thermostats tests of each sensor, as well as their coupling, at different temperature levels, provided several times at 2 month intervals have shown a resolution of 1 byte $\left(0.0625^{\circ} \mathrm{C}\right)$, a precision of $0.1^{\circ} \mathrm{C}$, a good reproducibility and a maximal derive between sensors registered values of 0.19 bytes, that may be considered as not significant (Figure 2).
In all the cases (except healthy volunteers) the rectal catheter was introduced after sedation or anaesthesia. Glycaemia was measured every $30 \mathrm{~min}$ in rats, every hour in men, either by strips (One TouchVerio IQ, LifeScan, Switzerland) or by gasometer apparatus (ADL90Flex) during operation in clinics. Both methods traditionally show an error of $2 \%$ of the indicated ciphers, according to the manufacturers' documents.

\section{Figure 2.}

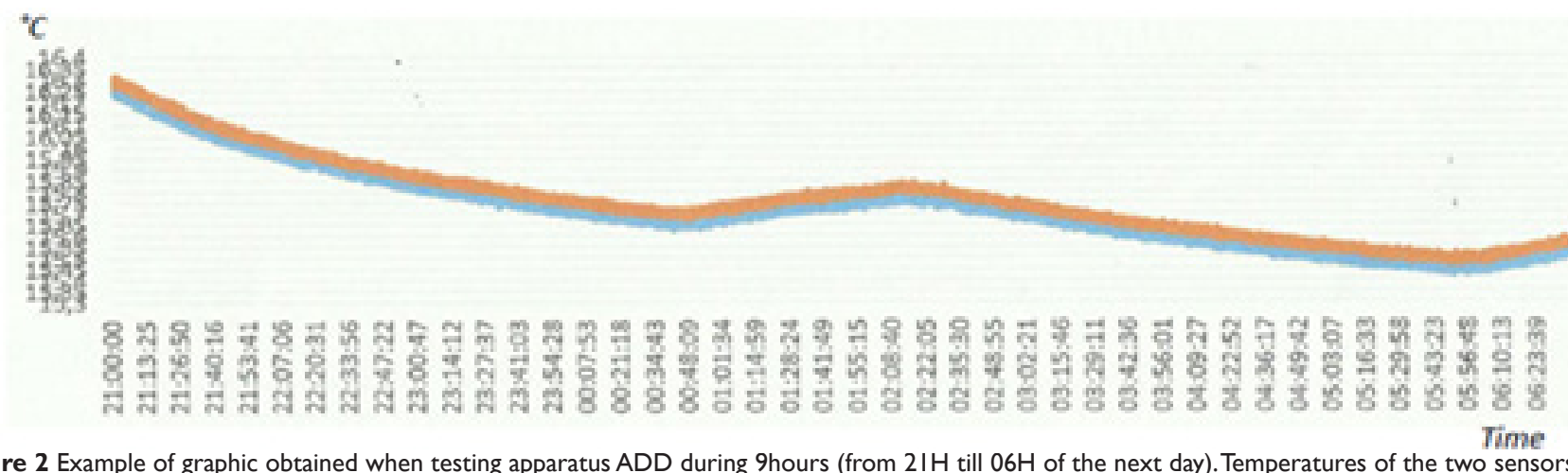

Figure 2 Example of graphic obtained when testing apparatus ADD during 9hours (from $2 \mathrm{IH}$ till $06 \mathrm{H}$ of the next day). Temperatures of the two sensors have changed in the same way (error $=0.19$ byte, $=0.003^{\circ} \mathrm{C}$ ), so DT is stable and constant.

Blue line, deep/core temperature; Red line, superficial temperature. Ordinate-bytes ( I byte $=0.0625^{\circ} \mathrm{C}$ ), abscissa Clock time in hours and minutes.

For statistic evaluation Mean values \pm Standard Deviation were calculated and Student criterion Td versus Tst was applied for determination of liability (p). Involvement of other not parametric statistic was considered but did not change the results. Correlation between dT and glycaemia was not systematically calculated considering the probable discordance in time of the two parameters. ${ }^{21,22}$

All the manipulations on animals were provided according to the rules of animal welfare and the local Ethics Committee (protocol $\mathrm{N}^{\circ} 420 \mathrm{~N}$ ). When required, euthanasia was performed by anaesthetics overdose. Clinical investigations were also allowed by the Ethic Commission of the CHU Brugmann (Brugmann University Hospital Center), Brussels.

\section{Results}

The procedure of temperature registration was well tolerated by both humans and animals. In some rats after more than 3 hours observation signs of intestinal engorgement were to be noted due to the partial obstruction by a relatively large for them catheter. However after awakening no complication was observed.

In experiments, during anaesthesia only, both temperatures rapidly decreased, Tc first, then Ts within a few minutes (Figure 3A\&B). So $\mathrm{dT}$ remained rather stable (variation was not significant). It is to be noted that the first recorded temperatures within 10-20min after the anaesthesia initiation were already relatively low: from $33.8 \pm 0.6^{\circ} \mathrm{C}$ to $35.74 \pm 1.27^{\circ} \mathrm{C}$ in different groups considered. Sudden increase or decrease of DT could correspond respectively to awakening or to degradation of the rat condition. Decrease of Tc fewer than $32^{\circ} \mathrm{C}$ level because of refreshment or due to anaesthetics overdose was often irreversible (Figure 3C).
Addition of a warming lamp or administration of glucose $5 \%$ or $10 \%$ subcutaneously or per os $(0.2-0.4 \mathrm{ml})$ had an immediate positive effect on temperatures and dT, (Figure 3D\&3E).

During anaesthesia only in half of the cases glycaemia increased up to pathologic levels $(149-230 \mathrm{mg} / \mathrm{dl})$ and within 2-3hours decreased, often up to normal level (Figure 3B). Low glycaemia $(<70 \mathrm{mg} / \mathrm{dl})$ was, as a rule, irreversible and a sign predicting a lethal issue.Warming the animal have no immediate effect on glycaemia and a glycaemia decrease was observed in some cases. It is also to be noted that initial glycaemia values in different groups did not significantly differ (N total=30, M=135.7, $\mathrm{SD}=17 \mathrm{mg} / \mathrm{dl}$; for different groups=129.6 \pm 203 ; $149 \pm 18 ; 140 \pm 20 ; 125 \pm 9,44)$, but the error $\mathrm{SD} / \mathrm{M}$ varied from $7 \%$ up to $14 \%$.

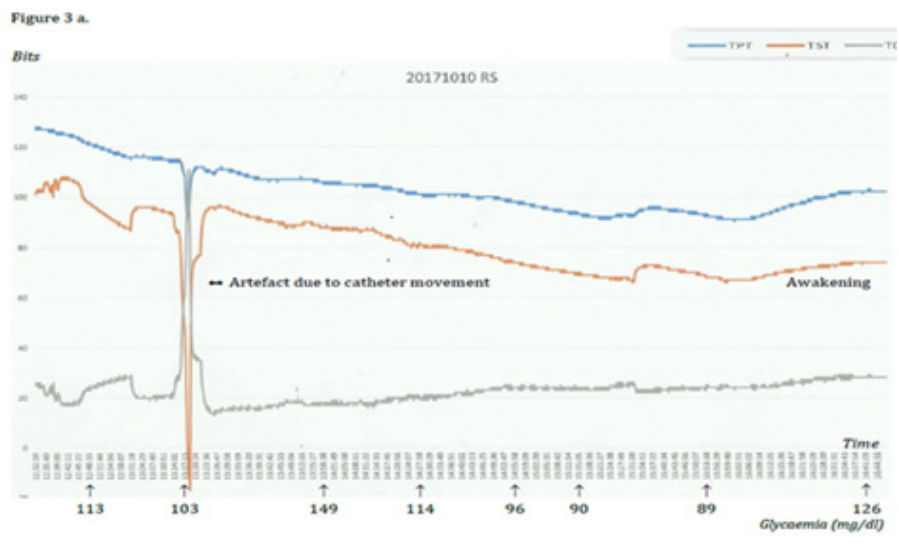




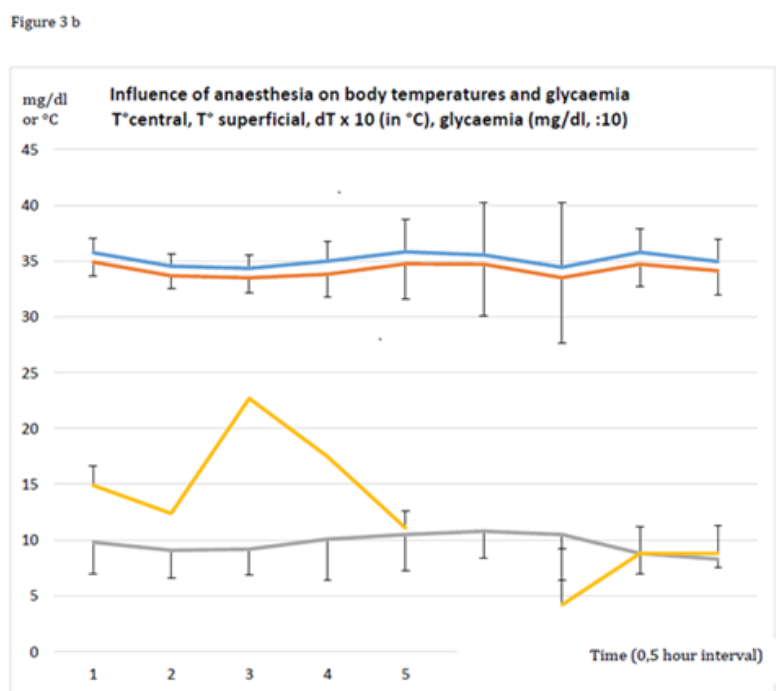

Figure 3A\&B Influence of anaesthesia only on body temperatures and glycaemia in rats (examples and graphics)

Example (a) and graphic (b) of the evolution of temperatures and glycaemia during anaesthesia in rats without external intervention, issue - awakening. Figure $3 \mathrm{c}$

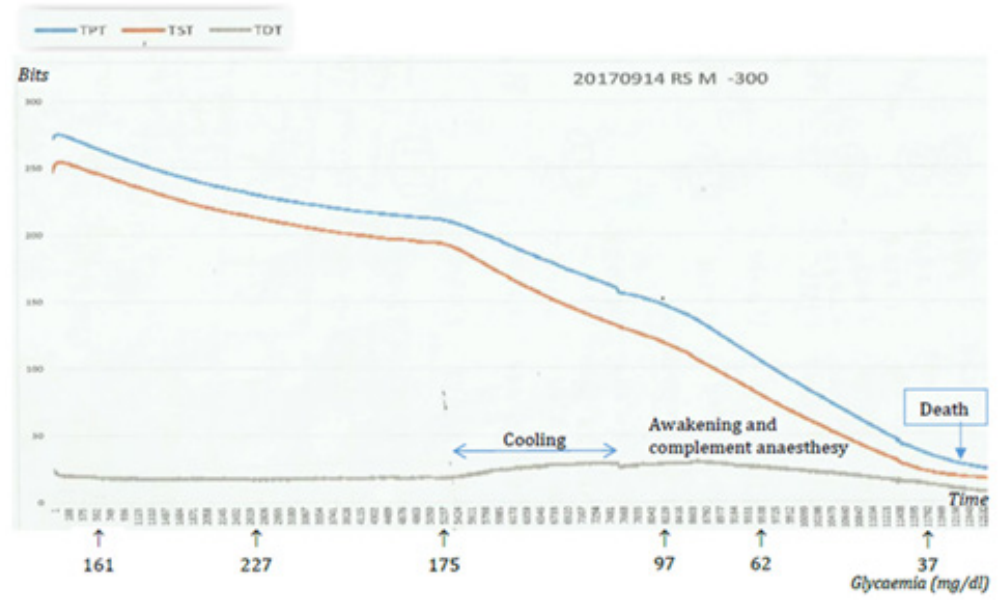

Figure 3C Lethal issue after cooling and complementary anaesthetics administration.

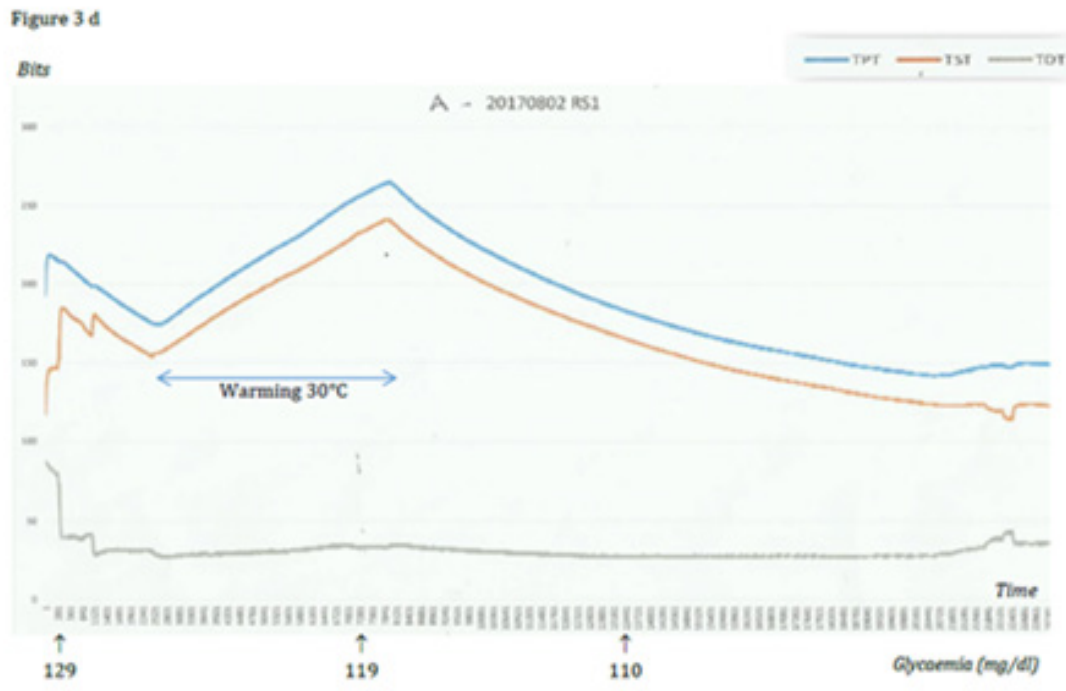



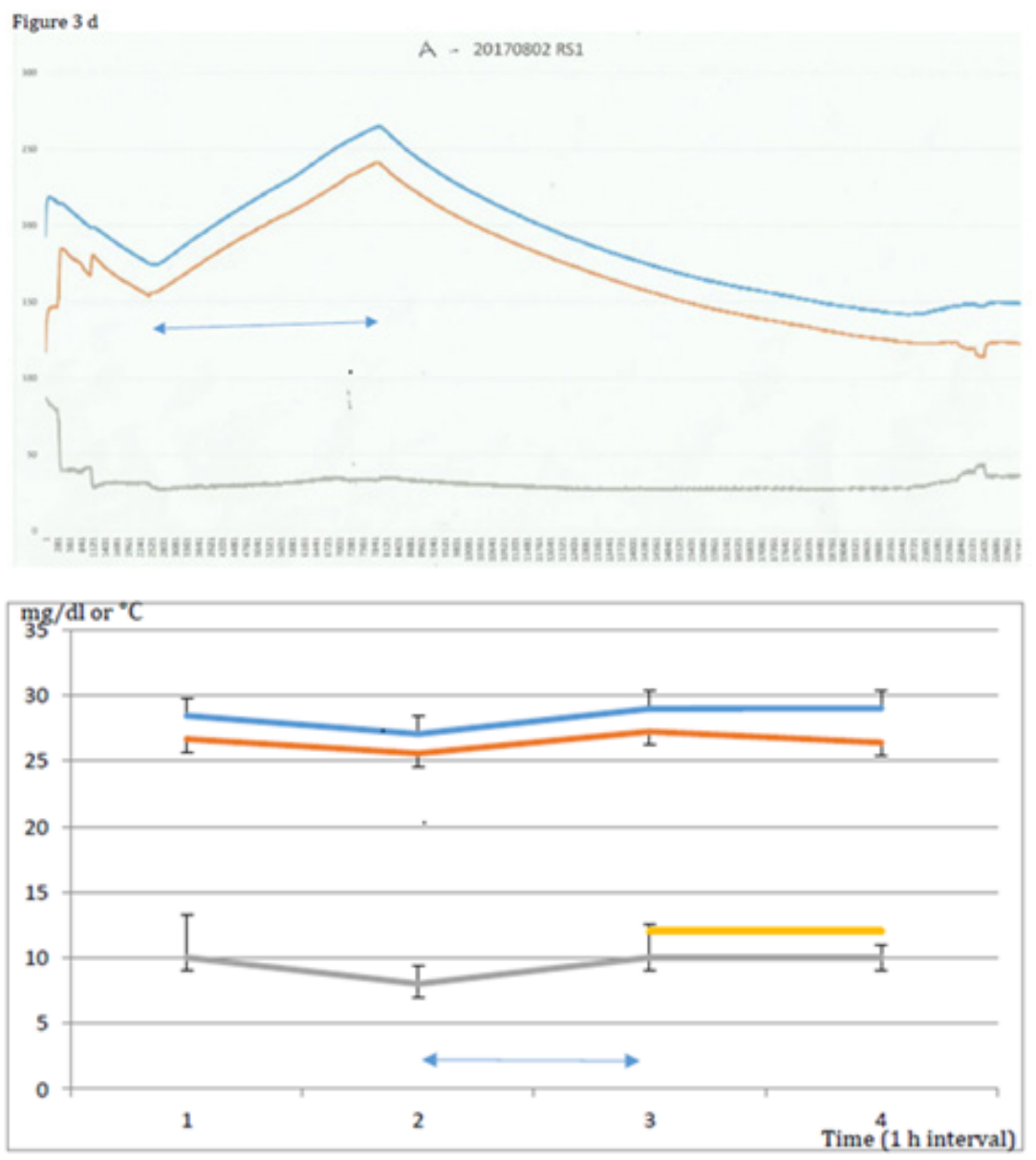

Figure 3D\&E Example and graphic of the influence of warming by a lamp: quick elevation of temperatures and DT, glycaemia slightly diminishing or stable.

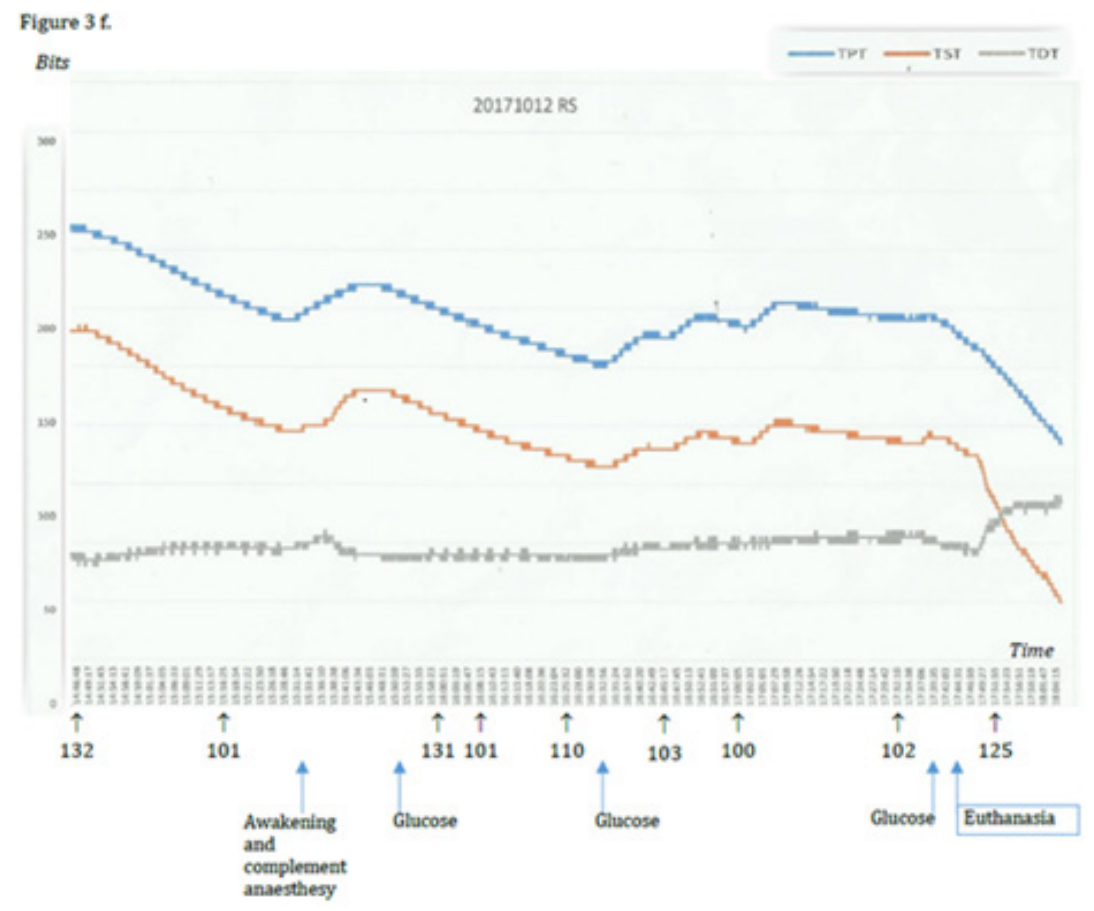

Figure 3F Influence of repeated glucose administrations: increase of the body temperatures, the core one first, no significant influence on glycaemia. Core temperature - blue, superficial temperature - red, dT - green, glycaemia - orange Time on graphics in 30min intervals. 
Analogous alterations were observed after surgery* in rats, may be with a more important temperature decrease probably due to the thoracic or abdominal cavity opening, and a more significant glucose level increase (up to $350 \mathrm{mg} / \mathrm{l}$ ) (Figure $4 \&$ Table 2). Interesting to note that a coming back to $\mathrm{Tc} 34^{\circ} \mathrm{C}$ and glycaemia $100-120 \mathrm{mg} / \mathrm{dl}$ was a positive sign, even a condition, of the animal awakening and successful surgery issue (Figure 4). On the contrary, low temperatures and low glycaemia were always present before lethal issue (Table 3).

A.

\section{Influence of anaesthesia and thoracic surgery on deep body temperature and glycaemia (favorable issue) $\mathrm{Tc}\left({ }^{\circ} \mathrm{C}\right)$, Glycaemia $(\mathrm{mg} / \mathrm{dl})$ divided by 10}

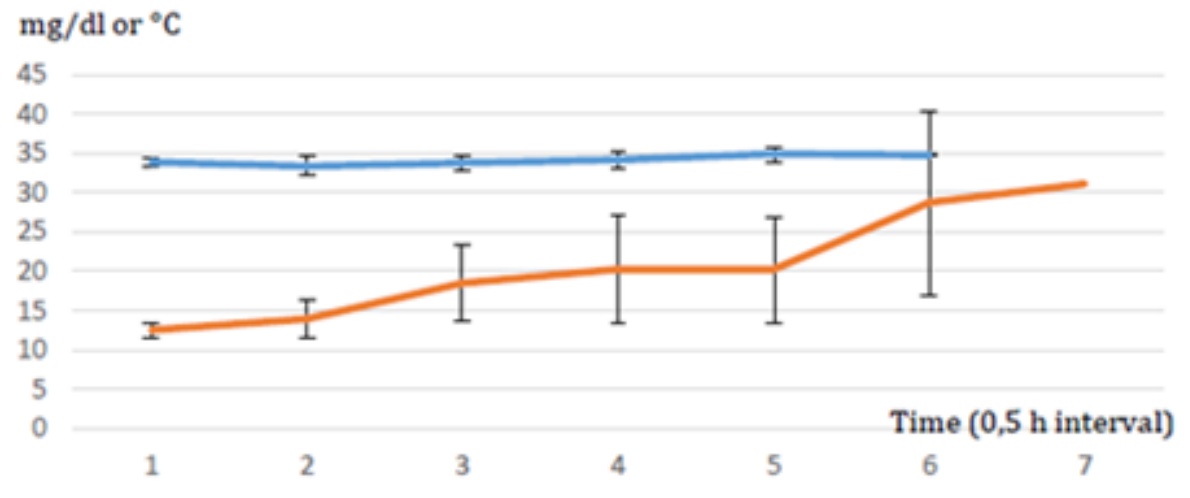

Figure 4A With favourable issue: increase of both indices at the end of observation.

Table 2 Glycaemia evolution after anaesthesia, before and soon after thoracic surgery in rats $(\mathrm{N}=14)$

\begin{tabular}{|c|c|c|c|c|}
\hline \multirow{2}{*}{ Time } & \multirow{2}{*}{ Glycaemia mg/dl } & \multicolumn{2}{|c|}{ Glycaemia ranges (mg/dl) } & \multirow{2}{*}{-Total number } \\
\hline & & $<100$ & $>150$ & \\
\hline Before intubation & $115.9 \pm 11.5$ & 0 & 0 & 10 \\
\hline After intubation & $142 \pm 24$ & 0 & & 16 \\
\hline $\begin{array}{l}\text { After operation } \\
30 \mathrm{~min}\end{array}$ & $143 \pm 40$ & 2 & 5 & 15 \\
\hline $\begin{array}{l}\text { After operation } \\
60 \mathrm{~min}\end{array}$ & $157 \pm 90$ & 1 & 10 & 14 \\
\hline $\begin{array}{l}\text { After operation } \\
90 \mathrm{~min}\end{array}$ & $189 \pm 138$ & 1 & 9 & 13 \\
\hline $\begin{array}{l}\text { After operation } \\
120 \mathrm{~min}\end{array}$ & $273 \pm 126 * *$ & 0 & 5 & 13 \\
\hline $\begin{array}{l}\text { After operation } \\
150 \mathrm{~min}\end{array}$ & $289 \pm 86 * *$ & I & 5 & 8 \\
\hline $\begin{array}{l}\text { After operation } \\
180 \mathrm{~min}\end{array}$ & $254 \pm 27 * *$ & 2 & 4 & 8 \\
\hline
\end{tabular}

$\mathrm{p}<0.05^{*} ; \mathrm{p}<0.01 * *$ relatively to values obtained before intubation

Table 3 Decrease of glycaemia and body temperatures during the hours preceding lethal issue $(\mathrm{N}=7)$

\begin{tabular}{|c|c|c|c|c|}
\hline Timellndices & $\mathrm{Tc}\left({ }^{\circ} \mathrm{C}\right)$ & $\operatorname{Ts}\left({ }^{\circ} \mathrm{C}\right)$ & $\mathrm{dT}$ in ${ }^{\circ} \mathrm{C}$ & Glycaemia (mg/dl) \\
\hline $\mathrm{HO}$ († moment) & $33.11 \pm 1.12^{* *}$ & $31.19 \pm 1.49 * *$ & $2.08 \pm 1.09$ & $90.4 \pm 33.1$ \\
\hline $30 \mathrm{~min}$ before $\uparrow$ & $33.6 \pm 0.90 * *$ & $32.2 \pm 0.83 *$ & $1.5 \pm 0.835$ & $113.4 \pm 42$ \\
\hline $60 \mathrm{~min}$ before $\uparrow$ & $34.0 \pm 0.58 *$ & $32.8 \pm 0.93$ & $2.15 \pm 1.05$ & $136.7 \pm 37.5$ \\
\hline $90 \mathrm{~min}$ before $\uparrow$ & $34.57 \pm 0.60$ & $32.2 \pm 0.92$ & $2.21 \pm 0.48$ & $157.8 \pm 32$ \\
\hline $120 \mathrm{~min}$ before $\uparrow$ & $34.88 \pm 0.28$ & $32.99 \pm 0.35$ & $1.99 \pm 0.30$ & $121.3 \pm 13$ \\
\hline Initial values & $35.6 \pm 1.25$ & $34.88 \pm 2.07$ & $1.932 \pm 0.953$ & $134 \pm 25$ \\
\hline
\end{tabular}

$\mathrm{p}<0.05 *$; $<<0.0$ I $^{* *}$; relatively to initial values

Tc, Core Temperature; Ts, Superficial Temperature; $d T=T c-T s ; ~ † d e a t h$ 
It was to be noted an absence of correlation between temperatures and glycaemia, except in the period of the life end, when the fall of both indices was quasi parallel (Figure $3 \& 4$ ).

In healthy humans glycaemia remained between 90 and $120 \mathrm{mg} /$ $\mathrm{dl}(\mathrm{SD} \pm 9$ till \pm 22$)$; body temperatures slightly decreased but remained higher $36^{\circ} \mathrm{C}$ and dT also decreased but was always positive (no food supply during the 4hour session) (Figure 5A).

In clinics, during digestive surgery, which ran without major difficulties or complications and had a favourable issue, body temperatures and dT have shown two patterns of variations. First when
Tc and Ts remained at acceptable levels and dT was no less than 50bytes $\left(0.3^{\circ} \mathrm{C}\right)$ and was always positive (2patients aged 60 and 66years). The second pattern consisted in a significant Tc decrease leading to negative dT soon after the surgery beginning and maintaining during the whole intervention (3patients aged 80-84years). For the 5patients the management conditions-air temperature, warming, adequacy of anaesthesia, and intra venous Hartmann perfusion - were analogous.

Abdominal surgery have shown the same tendencies than thoracic surgery but the survival varying between 0.5 and 1.5 hour, the results have been included only partly in Table 3 .

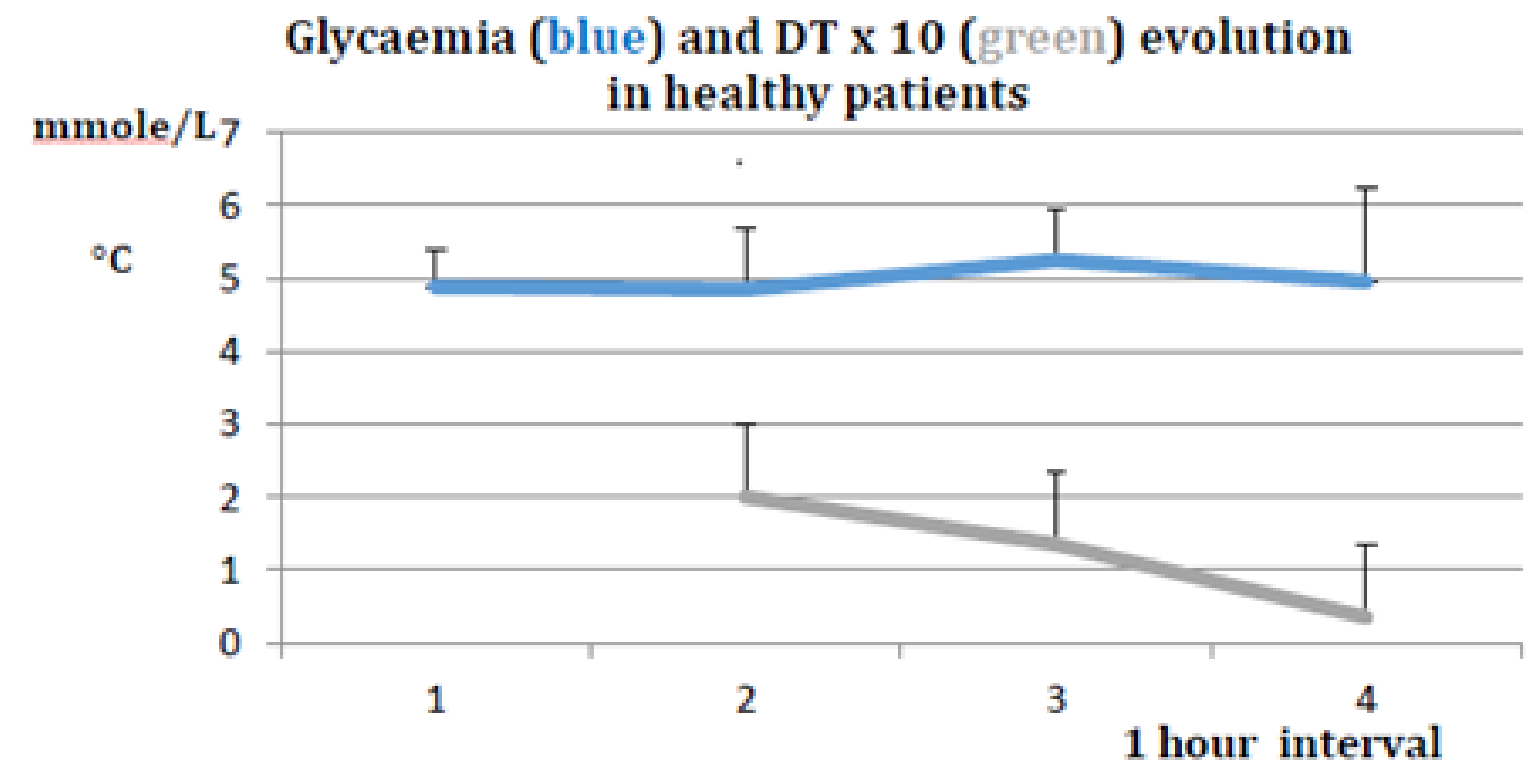

Figure 5A Healthy persons. DT decrease at the end of session.

Figure 5 B a

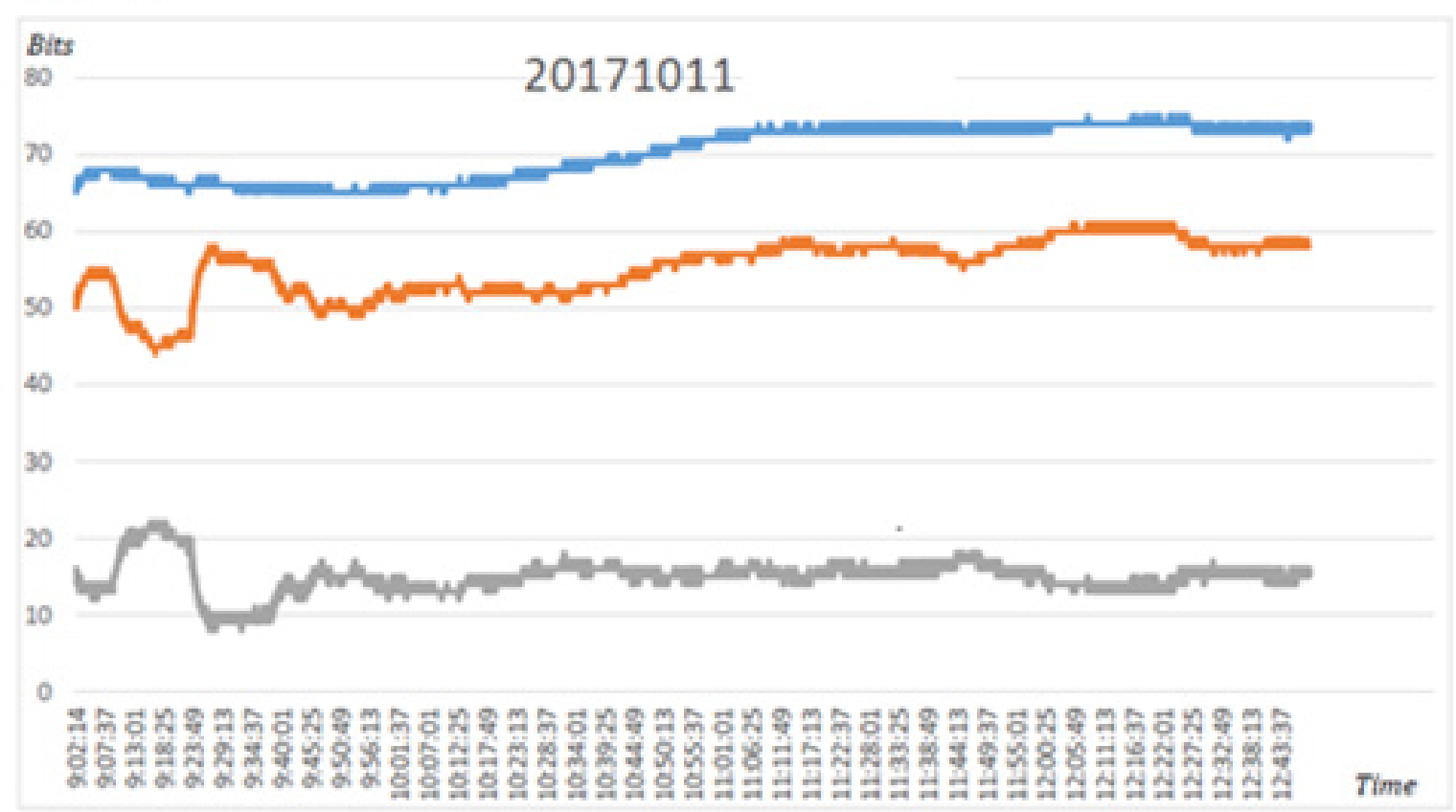




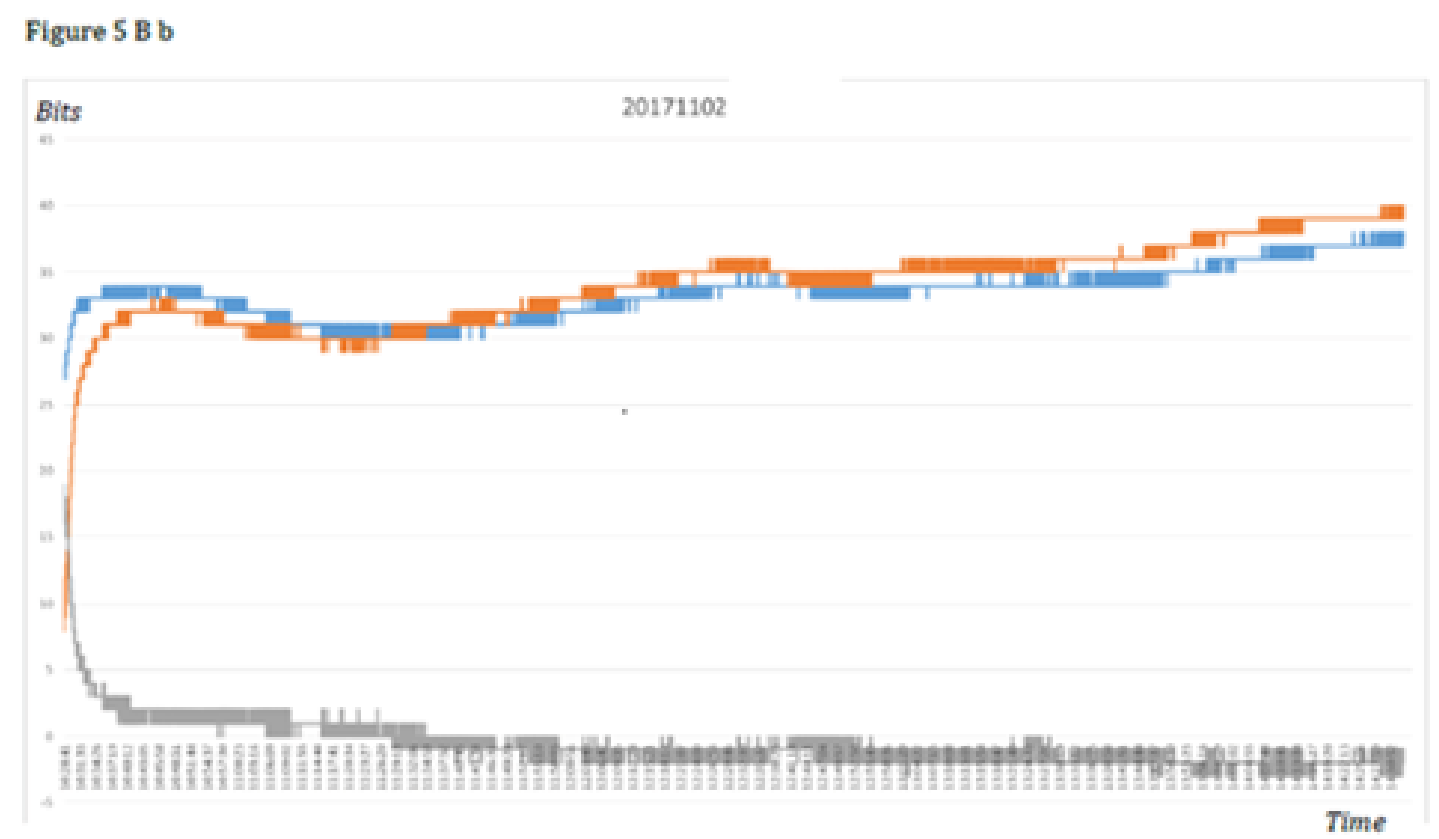

Figure 5B Examples of two different patterns ( $A$ and $B$ ) of patient's body temperatures and $\mathrm{dT}$ reaction during surgical intervention.

Figure 5 Evolution of DT in humans.

\section{Discussion}

Though our data are preliminary their analysis allows some reflexions.

There is to be noted that statistic analysis of our data has shown an important variability of the investigated indices, especially glycaemia and $\mathrm{dT}$, (even for control values error $>10 \%$ ). It cannot be explained by investigation methods weakness which marge of error was $<2 \%$, An insufficient observation number is not probable, because the total number of initial glycaemia (Gi) determinations after anaesthesia but before any other manipulation, was $30(\mathrm{M} \pm \mathrm{SD}=137.5 \pm 17.2 \mathrm{mg} / \mathrm{dl})$ and the variations between the above mentioned global results and Gi of different observation groups were not significant (see results in experiments, §3). The conditions of observation were maximally standardized. Nevertheless the reactions of different animals began at different moments and developed with different rates, and that could be a cause of statistics difficulties, which we tried to avoid in Table 3, beginning the report from the end point. These variations could also be due to individual characteristics of the animal glucose and energetic metabolism (including glycogen reserves, functional capacities of the insulin and contra insulin system, reactivity in shock, stress or other pathologic situations), which we could not assess. The observed individual responses to the tests even performed on laboratory animal in standardized conditions deserve further study.

Body temperature measures were, at the contrary, more reliable (error $<5 \%$ ), nevertheless dT (Tc-Ts) variability was high (error often $>10 \%$ ). We know that Tc and Ts evolution was different: Ts evolution was slower than Tc one and probably depended on organ and tissue energetic needs also conditioned by the blood flow intensity (which unfortunately we could not measure). That may explain complementary dT variations of different amplitudes. Anyway, the phenomenon remains not quite clear and requires further investigation.

It is the reason why, in the analysis of our results, we have considered as well the group tendencies and the individual evaluations.
We have also considered as basic control ciphers $\mathrm{Tc}>35^{\circ} \mathrm{C}$, Ts $>33.5^{\circ} \mathrm{C}, \mathrm{dT}>0$ and glycaemia between 90 and $140 \mathrm{mg} / \mathrm{dl}$. For bio ethics reasons all our initial ciphers were obtained after complete anaesthesia, so the temperatures were already decreased. In thoracic surgery the relatively stable rectal temperature was probably linked with constant table warming of the animals (Figure 4).

Anaesthesia is known to cause body temperature decrease. ${ }^{1-4}$ and this was confirmed in our experiment. This effect seems to be independent on the drugs involved, which, in our work, were different in humans (mainly Sulfentanyl ${ }^{\circledR}$ ) and in animals (mainly barbiturates), unless different drugs led to analogous metabolism depletion.

The anaesthesia only had also influenced the glycaemia, but the reactions were opposite: increase in the majority of the cases, decrease in some ones. This difference of reactions in animals of the same strain, sex, BW is difficult to explain except considering the preliminary endogenous glucose reserves, other parameters such as hormonal (insulin, catecholamine, glucagon) accessibility and other factors which are not easy to determine and obtain quick results. This would be confirmed by some clinical observations in ICU which have shown that the reported hyperglycaemia could correspond to different levels of blood insulin contents. ${ }^{12}$

In animals after anaesthesia and surgery, temporary hyperglycaemia was more frequent and more important, than after anaesthesia only. This was probably due to the influence of intubation and operative stress, and corresponds to literature data concerning acute critical care. $^{5-9}$

Taking into account the concomitant variations of glycaemia, Tc, Ts and dT, it was clear that when both temperatures, dT and glycaemia were falling, the vital prognosis was bad (lethal) - see Figure 3C, that confirms some literature data about negative effect of a too strong observance of glycaemic regimen. ${ }^{5,10,11}$ A marked tendency to normalization of these indices was practically a condition for anaesthesia and surgery favourable issue (Figure 3A,D,E \& Figure 
4A). Was it due to the end of anaesthetics effect or to adequate support of energetic balance as in Figure 3F in animal or Figure 5A in clinics? that is still to be determined.

It was also observed that temperature reaction to condition modifications, such as warming, cooling, glucose administration, were quick (within a few minutes), whereas glycaemia changed significantly later (Figure 3F). This confirms other literature data. ${ }^{19-22}$ Correlation between glycaemia and temperatures was sometimes direct - at the life end, or in healthy persons, for instance. It was often inverse and not permanent (Figure 3).

The observation that glycaemia changes seemed to develop more slowly than temperature ones, supports the hypothesis that temperature measures and especially $\mathrm{dT}$ (Tc thermogenesis and Ts thermic "outlay") reflect the very energetic process whereas the glycaemia, especially venous (measured in our animals) reflects the amount of remaining free, after distribution in the organs and tissues, not yet used "combustible" that is the result of the process.

From this point of view, it is possible to suggest an interpretation of some observed results. If glycaemia was high it meant that either glycogenesis was boosted - then Tc and dT must be increased, or glucose utilization is diminished and Ts decreased and $\mathrm{dT}$ increased. Hypoglycaemic situations might be the result either of decreased thermogenesis - then Tc was low and dT may be $<0$ (for instance in animals at the end of the life or in decompensated type 1 diabetic patients) ${ }^{23}$ or of increased glucose utilization by the tissues (as in hungry or tired healthy persons). ${ }^{16,19}$ and then Ts was stable or relatively high and glycaemia also kept stable. Insufficient thermogenesis might be the explanation of dT $<0$ in the second group of our patients. Is it possible that glucose (and insulin?) complements could correct their supposed "energetic" deficit?

As far as Tc, Ts and dT may be registered in continuum and their sensibility to internal and external condition variations seems high, the use of temperature registration during surgery (ADD device) could be useful for the early detecting the possible patient's condition degradation and then for correction of the anaesthesia management The start points should be maintaining Tc no less than $35-36^{\circ} \mathrm{C}$ and dT positive values without yo-yo phenomenon by means of automatic monitoring of glucose (and insulin?) administration as it was realized in the treatment of acute disorders of the glucose metabolism using this "energetic feedback" for monitoring insulin treatment. ${ }^{15-20}$ The precision and resolution capacities of the ADD device having satisfied the required accuracy, thanks to digital technique and differential calculation of $\mathrm{dT}$, they might warrant an adequate adaptation to individual characteristics of the patient "energetic" metabolism.

This demands confirmation in further cautious and accurate studies.

\section{Conclusion}

Both anaesthesia and surgical intervention were confirmed to influence significantly both glycaemia and body temperatures i.e. glucose metabolism and energetics of the organism, operative shock deepening the effects of anaesthesia.

Though the registered values of dT and glycaemia values did not correlate, at least in time, simultaneous registration of these markers during anaesthesia and surgery seems to be appropriate for the physiological change detection and understanding.
The ADD device has shown itself liable and accurate as a testimony of temperature production and release that is of the organism energetic balance.

The ADD use in per operation conditions may be useful for rapid detection of general condition degradation.

The obtained data allow to consider the possibility of using the "energetic" feedback to monitor both insulin and glucose administration for an adequate and quick modulation of the necessary correction and monitoring of the patient's condition.

\section{Acknowledgements}

The authors express their thankfulness to Professors $\mathrm{Ph}$ Vanderlinden (Anaesthesiology), L Bruyninx (Digestive Surgery) for their support, Drs F Mboti (Digestive Surgery), and J Bidgoli (Anaesthesiology) for their participation to the first operations with ADD use in the CHU Brugmann. We are grateful to Ms M Leroy (IPG, Gosselies, Belgium), To Mr A Bekkouri (ULB) to Mr J-L Kempeneers for their logistic help.

\section{Conflicts of interest}

The authors declare that there are no conflicts of interest.

\section{Funding}

None.

\section{References}

1. Grote R, Wetz AJ, Bräuer A, et al. Prewarning according to the AWMF S3 guidelines on preventing inadvertent perioperative hypothermia. Anaesthesist. 2017;67(1):27-33.

2. Monteiro FLJ, Halpern H, Bortoli F, et al. Forced air-warming in patients undergoing endovascular procedures. Comparison between 2 thermal blanket models. Ann Vasc Surg. 2017;50890-5096(17):30028-30036.

3. Schuster CJ, Pang DSJ. Forced air pre-warming prevents perianaesthetic hypothermia and shorters recovery in adult rats. Lab Anim. pii: 23677217712539 .

4. Epstein FH, Dexter F, Hofer IS, et al. Perioperative temperature measurement consideration relevant to reporting requirements for National Quality Programs using data from Anaesthesia information management system. Anesth Analg. 2017;126(2):478-486.

5. Ouattara A, Benhaoua $\mathrm{H}$, Mabrouk N. Equilibre glycémique strict en anesthésie - réanimation. MAPAR, 240-252. 2017;247-252.

6. Van den Berghe G, Wouters P, Weekers F. Intensive insulin therapy in critically ill patients. 2001.

7. Van den Berghe G, Wilmer G, Hermans G, et al. Intensive insulin therapy in the medical ICU. 2006

8. Van den Berghe G, Wilmer A, Milants I, et al. Intensive insulin therapy in mixed medical/surgical intensive care units: good versus harm. Diabetes. 2006;55(11):3151-3159.

9. Thomann R, Keller U. Hyperglycémie dans les maladies aiguës - un risqué sucré. Forum médical Suisse. 2012;6:1051-1054.

10. Hirsch B. Understanding low sugar from NICE-SUGAR. NEJM. 2012;367:1150-1152.

11. Kavanagh BP. Glucose in the ICU - Evidences, guidelines and outcomes. NEJM. 2012;1259-1260. 
12. Panza-Nduli J, Coulic V, Willems D, et al. Influence of bedside insulin measurement on acute coronary syndrome pathways. Critic Pathways Cardiology. 2011;10(4):185-188.

13. Schmid TRF, Tes G. Human Physiology. Moscow, ed "Nauka". 1986;4.

14. Novikov VK, Coulic VP. Méthode/Procédé de diagnostic du diabète sucré. Moscou 15.11.1991 Brevet no 1718822. 1987.

15. Coulic V, Novikov V, Devriend TJ, et al. Use of temperature gradient measuring device in monitoring of diabetic and critically ill patients" in "Sciences and Technologies for Health., abstract FrP2C1.3 (29 ${ }^{\text {th }}$ Annual International Conference of the IEEE in conjunction with the Biennial Conference of the SFGBM, Lyon, France. 2007;372.

16. Tarabarko NV, Novikov VK, Rjevskaya ON. Surgical treatment of Diabetes Mellitus. Viestnik Transplantologyi y Iskustvennykh Organov. 2006;8(4):23-30.

17. Tarabarko NV, Novikov VK, Rjevskaya ON. Combined transplantation of a kidney and pancreatoduodenal complex in the treatment of Diabetes Mellitus. Viestnik Transplantologyi y Iskustvennykh Organov. 2007;9(5):8-14.

18. Novikov VK, Vietluguina MA, Maïssiouk Ia G. Correction of carbohydrate metabolism by using the apparatus of insulin therapy in patients with type I Diabetes Mellitus after renal transplantation. Viestnik Transplantologyi y Iskustvennykh Organov. 2012;14:72-76.
19. Novikov V, Anissimov Iu, Dmitriev I, et al. Differential Temperature Evolution for Insulin Delivery Monitoring in Type 1 Diabetic Patients before and after Kidney-Pancreas Transplantation. International Journal of Diabetes \& Clinical Diagnosis. 2016.

20. Novikov VK, Dobos SA, DevriendT J, et al. "Energetic balance" feedback for insulin delivery monitoring applied to hyperglycaemic non diabetic type I patients. WCDT. 2017.

21. Harvey RA, Dassau E, Zisser H, et al. Design of the health monitoring system for the artificial pancreas: low glucose prediction module. $J$ Diabetes Sci Technol. 2012;6(6):1345-1354.

22. Facchinetti A, Sparacino G, Guerra S, et al. Real-time improvement of continuous glucose-monitoring accuracy: the smart sensor concept. Diabetes Care. 2012;36(4):793-800.

23. Coulic V, Novikov Vi, Devriendt J, et al. Use of temperature gradient measuring device in monitoring of diabetic and critically ill patients" in "Sciences and Technologies for Health" 2007. Abstract FrP2C1.3 (29 Annual International Conference of the IEEE in conjunction with the Biennial Conference of the SFGBM, Lyon, France. 2004;372. 